\title{
Gender and forestry in Uganda \\ Policy, legal and institutional frameworks
}

\author{
Concepta Mukasa', Alice Tibazalika', Alice Mango' and Harriet Nabirye Muloki'
}

\section{Key messages}

- Despite legal frameworks, policies and strategies in Uganda to support equality between men and women, prominent gender inequalities still exist in forest use and/or management.

- Cultural beliefs and traditional practices that restrict women from planting trees or from speaking in public forums constrain policy implementation.

- Initiatives set up by the government to support private tree planting require land ownership, yet women own only $7 \%$ of land in Uganda. This automatically excludes them.

- Most gender mainstreaming policies lack legal provisions to ensure compliance, and gender considerations in national laws are not reflected at lower levels of government.

- The forestry sector and civil society organisations should encourage girls to pursue a career in science, and forestry in particular.

- The National Forestry Authority should work with civil society, the private sector and development partners to address gender concerns in forest management; simplify guidelines for community forest management and produce them in local languages; and advance funding to women to help them take part in private forest development and central forest reserves.

\section{Introduction}

Uganda continues to lose an estimated 80,000 ha of forest every year (Tenywa 2008). Fuel wood accounts for about $90 \%$ of the energy consumed in Uganda so, not surprisingly, about 95\% of the lost forests are consumed as fuel wood. With a population growth rate of 3.2\% per year, the annual domestic consumption of wood is expected to increase (UBOS 2009).

1 Association of Uganda Professional Women in Agriculture and Environment (AUPWAE).
The decline in forest cover is expected to continue, principally due to agricultural expansion and cutting for fuel wood. Many areas of the country are already deforested and subject to increased erosion, landslides, siltation of rivers, pollution of surface waters and uncontrolled disposal of solid waste. This deterioration has gender implications as women continue to bear the burden of walking longer distances for water, food and fuelwood.

Since the late 1990s, government law reforms in Uganda - including those relating to forestry and natural resource management - have generally recognised gender-related issues and the importance of women's participation in the management of development programmes. This infobrief summarises a study of the institutional, legal and policy frameworks in Uganda that govern natural resource management/forest management and how these address gender equality considerations. It includes highlights of gender integration practices in the natural resources sector, focusing specifically on forest use and management.

\section{Legislative and policy architecture}

At the international level, Uganda has ratified and signed several global accords on gender equality and women's empowerment, including the Convention of Elimination of All Forms of Discrimination against Women (CEDAW) and the Beijing Platform of Action. In addition, Uganda has pledged to implement the United Nations Millennium Development Goals, which include the promotion of gender equality, by 2015. The country is also a signatory of the African Charter on Human and Peoples' Rights (1986) and to the Protocol to the African Charter on Human and Peoples' Rights on the Rights of Women in Africa that came into effect on 25 January 2005.

Uganda has also ratified international protocols to promote sustainable forest management and community empowerment. The Convention on Biological Diversity, for example, promotes indigenous knowledge and recognises the vital role women play in conservation and sustainable use of biodiversity.

At the national level, Uganda has several policies, legal and institutional frameworks to support equality between men and women, including the Constitution, the Uganda Gender 
Policy, the National Environmental Management Policy, the Water Policy, and the Uganda Forestry Policy. A multitude of institutions manage forest resources, led by the Forestry Sector Support Department (FSSD) in the Ministry of Water and Environment (MWE) and the National Forestry Authority (NFA) a semi-autonomous body under the MWE.

Since 2001, Uganda has adopted participatory approaches to engage both communities and the private sector in forest management: these mechanisms are described below. These approaches are supported (with varying degrees of success) by strategies and policies ranging from the National Development Plan to the National Forest Plan.

\section{Collaborative forest management}

Through the National Forest Plan (NFP), Uganda has adopted collaborative forest management (CFM) to enhance community participation and local partnerships. Through CFM, community members enter into a Memorandum of Understanding (MoU) with the NFA to manage part or all of a gazetted central forest reserve (Wasswa-Matovu 2010).

Community-based organisations involved in CFM and NRM are organised in six networks and manage about 6,498 ha with 1,757 household involved in some form of collaboration. Communities with CFM agreements receive small grants for income-generating activities like beekeeping and honey processing, as well as free seedlings to plant trees around the forest reserve boundaries; they are also trained in various skills.

The CFM approach has significantly reduced unregulated activities, mainly due to social pressure in local communities. In Butto-Buvuma Central Forest Reserve in Mpigi, for example, increased community patrols (set up through the CFM) reportedly reduced illegal activities, especially tree cutting (Gombya-Ssembajjwe and Banana 2000a). In addition, communities passed bylaws to regulate harvesting, established three recreation sites within the forest to provide employment (especially for youth) and set up a market outlet for communitymade crafts. Five years after the study, however, the communities (especially youth who were not part of CFM) have intensified their illegal activities and completely degraded the forest. These degraded areas have now been leased to private investors for tree planting; women suffer because it is more difficult to obtain subsistence products from the forest.

As of June 2010, only 53 community organisations had signed MoUs with the NFA. On the other hand, district local governments have not adopted CFM due to funding constraints. Other issues with CFM identified by various studies include:

- an externally driven process with no local pressure groups demanding changes in the legal framework governing forest resources

- diversion of available labour from food production to tree management
- political interference, which leads to forest encroachment

- dominance of the process by the local elite

- benefits to local communities in the form of user rights for subsistence, rather than high value commodities, which is attributed to poor negotiation skills among the user groups

- long preparation and negotiation processes before CFM agreements are signed, leading to loss of interest

- lack of clarity in some agreements on boundaries for CFM

- lack of leadership by local governments in implementing CFM agreements, despite being signatories

- inadequate technical staff in the NFA to ensure thorough community engagement especially of women

- illegal timber harvesting in CFM sections by 'outsiders' who have licences.

CFM guidelines provide for gender equality. Although the NFA lacks gender-disaggregated data, a study on forestuser associations (Kazoora et al. 2006) revealed that formally recognised CBOs and farmer groups registered with the National Agricultural Advisory Services (NAADS) programme have entered into CFM agreements with the NFA. Since $60 \%$ of women in Uganda are farmers (Ellis et al. 2006), and are members of NAADS groups, women do seem to be involved in CFM activities.

Kazoora et al. (2006) found that men dominated the leadership of forest community-based associations. Although women constituted $61 \%$ of the founding members, only a few women held top leadership positions (and this was normally in womenonly associations). Indeed, according to Empaform (2006), CFM agreements address gender and equality merely to satisfy donors: some $80 \%$ of affected women don't understand the simplest CFM rules or their own rights. At the same time, Gombya-Ssembajjwe and Banana (2000b) found that women are not keen on managing forest reserves since it adds to their work burden.

The evidence points to several implications for women's participation in CFM.

- Women participate in CFM by virtue of being the majority in forest user-groups or members of groups under the NAADS programme.

- Community user-rights provided under CFM benefit women who are heavily dependent on non-timber forest products like water, fuel wood, food and medicinal plants.

- Women have limited influence in CFM as men dominate leadership positions.

- The lengthy process of negotiating CFM agreements results in many women losing interest due to their time constraints (Table 1).

- The limited interaction between communities and the NFA discourages women from participating in CFM activities.

\section{Community-based forest management}

Communities are also active in community-based forest management (CBFM) which occurs in non-gazetted forests 


\section{Table 1. CFM process}

\begin{tabular}{ll}
\hline Step 1 & Initiating the process \\
Step 2 & Preparing an application for CFM \\
Step 3 & Meeting between applicant and responsible body \\
Step 4 & Participatory situation analysis \\
Step 5 & Initial negotiation and drafting a CFM plan \\
Step 6 & Institutional formation and development \\
Step 7 & Continuation of negotiations \\
Step 8 & Review of the plan and agreement by stakeholders \\
Step 9 & Implementation \\
\hline
\end{tabular}

Source: Empaform (2006)

often found on customary land. Communal land associations (CLAs) sign Memoranda of Understanding/Agreements with the NFA to manage part or all of a non-gazetted forest reserve. In principle, CLAs may be the most advanced mechanism to ensure community control over resources and equitable sharing of benefits, but only two have been registered and awarded certificates of customary ownership.

One study revealed that community forests were often a source of water and firewood, especially for land-constrained households (Wasswa-Matovu 2010). At the same time, households wellendowed with farm implements and labour benefited more from community forests since they could more effectively extract resources and visited the forest more frequently. Apart from water and firewood, other key forest products included medicinal/ herbal plants, edible plants and livestock feed.

Another study (Kugonza et al. 2009) revealed that both men and women play an important role in managing forests outside protected areas. Men were more involved than women except for tree planting and nursery management (Table 2). Women were less willing to take part in CBFM activities due to men's unwillingness to cede power, higher illiteracy and women's already high work-burden.

\section{Community resource management}

Community resource management (CRM) takes place in forests in national parks or wildlife reserves where land/tree tenure is vested in the Uganda Wildlife Authority (UWA). The UWA signs MoUs with community associations or groups for access to some nontimber and non-wildlife resources (such as herbs, firewood, honey and mushrooms) within the national parks. Some groups also get involved in ecotourism by providing porters and tour guides.

UWA forests under CRM are threatened by agricultural expansion, unregulated pitsawing and overgrazing from pastoralists. In addition, the local government lacks capacity to manage forest resources. CRM linkages with local communities are well-defined, but are generally weak on benefit sharing.

\section{Private forest management}

While about $70 \%$ of total forest cover in the country is on private and customary land, policy frameworks have long neglected private forest management. As a result, private forest owners have used their constitutional rights to manage their resources often unsustainably. While landowners can engage in private forestry, there are widespread gender inequalities in land control and ownership. Despite provisions in the Land Act, for example, men still dispose of land without the consent of their spouses.

\section{Collaboration in the forestry sector}

The NFA has developed relations with various civil society organisations that deliver services ranging from training and capacity building to advocacy for responsible forest management. In addition, the NFA works with companies, parastatals and development partners that support tree planting as part of corporate social responsibility. Success stories include the Mugamba-Majanjabula Save the Forest Association, which

Table 2. Gender-based distribution of roles in community-based forest management (\%)

\begin{tabular}{lcc}
\hline Role & Men ( $\mathbf{n = 9 8 )}$ & Women $(\mathbf{n}=\mathbf{6 2})$ \\
\hline Tree planting and management & 78 & 79 \\
Nursery establishment & 38 & 60 \\
Monitoring forest activities, planning, formulation of policies & 30 & 15 \\
Responding to emergencies & 56 & 37 \\
Refraining from illegal activities & 33 & 26 \\
Protected area management & 13 & 6 \\
Participating in community education and activities, biomass & 17 & 2 \\
conservation technologies & & 12 \\
Other alternative sources of income (apiary, fishing) & & \\
\hline
\end{tabular}

Source: Kugonza et al. (2009) 
received funds from three sources to plant trees (D. Sebugwawo December 2011, personal communication), establish a herbal medicine nursery and strengthen its advocacy and leadership capacities.

\section{Women's participation in forestry}

A number of studies identified various factors that support, or impede, women's participation in forestry.

- Policy and legal issues. While Uganda has several policies that address women's participation in natural resources, these initiatives leave much to be desired in practice. The Constitution, for example, supports equality between women and men on all issues, but women, children and orphans are still treated unequally, especially in the area of asset ownership. The Uganda Forestry Policy ensures the integration of gender concerns and issues into the development of the forestry sector, but cultural beliefs such as the idea that "women are not supposed to plant certain tree species" interfere with implementation.

- Education. On the one hand, all three Ministers in the MWE, three Commissioners in the forestry sector and one-third of students in the School of Forestry are women. On the other, low-literacy levels for women at the grassroots level weaken their self-confidence and participation in forestry management.

- Economic status. Supportive policies have improved women's economic status, enabling them to buy land and manage natural resources directly (MoFPED 2005). Still, women own only $7 \%$ of land in Uganda, which directly affects their participation in private forestry.

- Traditional practices. With increasing awareness, people are realising that women and men are equal. Men are encouraging women to plant trees on family land, knowing the products will benefit the whole family.

- Social groups. Women who belong to social groups were found to adopt tree planting because of increased awareness and group pressure.

- Benefit sharing. Women do not have the right to plant and harvest commercial products because they don't own land and tree planting is a long time venture, which becomes a disincentive to participating in tree planting and management.

- Work burden. The unequal division of labour between the genders saddles women with more work. Women, especially the poor, work an average of 15 hours per day compared to an average of 9 hours daily for men (JICA 2007).

- Access to capital/credit. Initiatives set up by the government to support private tree planting require land ownership, which automatically excludes most women. Lack of land ownership also limits women's access to credit since lending institutions often demand land titles as collateral (M. Watasa 2010, personal communication).

- Decision making. Women can participate in forest management through CFM arrangements, but their influence is limited for various reasons. For example, men dominate the leadership and farmer fora of NAADS.

- Knowledge and skills. Some $80 \%$ of women, persons with disabilities, the old and the vulnerable in CFM agreements do not know their rights (Empaform 2006), leading men to often make decisions in their own favour (MWE 2002). Women's ignorance is connected both to poor education and their reproductive roles: unlike men who can get information from markets, bars and the media, women are more likely to stay on the farms (Katungi et al. 2006).

- Attitudes towards science. Girls generally hold negative attitudes towards forestry as a profession and towards science in general, leading to fewer women working in forestry. Affirmative action programmes have favoured the arts over science. Due to the isolation of the forests, women are reluctant to take on the 'unsafe' position such as forest ranger (M. Watasa 2010, personal communication).

- Cultural beliefs. Many traditional beliefs limit women's participation in forestry and tree management. In some regions, it is taboo for women to plant trees since this demonstrates land ownership. Some also believe that if women climb trees, the trees would stop fruiting or produce rotten fruit.

\section{Gender issues in practice}

Apart from the Ministry of Gender, Labour and Social Development (MGLSD) and the Africa 2000 Network, no other surveyed organisations had a written gender equity policy, focused specifically on gender or employed staff specifically responsible for gender. Most organisations interviewed referred to 'gender mainstreaming' in terms of attendance rather than full participation. When the NFA plans meetings, however, it does consider women's schedules and provides separate rooms for women where they can speak freely. Still, in most cases, men disregard women's suggestions. For Self Help Africa, implementation plans include activities that strengthen skills and provide women/girls and men/boys with equal access to services and training.

There are still prominent inequalities in gender and forest use and/or management. Since men own $70 \%$ of forest resources and government owns the rest, women rarely take part in decisions about forest use. Generally, women harvest products for subsistence use such as firewood, herbal medicine, water, vegetables and handicraft materials. In economic terms, most women benefit from forests indirectly through their husbands or male relatives.

The main obstacles to women's participation in forest management in Uganda are identified as the following:

- lack of provision for a gender position in organisational structures

- lack of a person (staff) assigned to work specifically on gender

- inadequate knowledge, information and skills on gender 
- lack of a gender policy and guidelines

- belief that forestry is considered a male domain

- belief that women lack physical strength and courage, which are required for most nonmanagerial forestry jobs

- low participation of women in science, which leads to fewer women decision makers in forestry

- no specific budget for gender activities in non-governmental organisations (NGOs) and the MGLSD allocated a very small budget compared to other ministries

- resistance from some men in the forestry sector to the few women who have tried to join the sector in various capacities, as well as the toughness of some forest activities.

Of 16 past and present projects/programmes, $44 \%$ focused on gender, 25\% focused on women specifically and 31\% focused on communities in general. A 'gender project' that promoted sustainable natural resource management was successful in part because most of the peer educators were women. Another successful gender project identified tree species desired by men and women, and then set up separate nurseries that met their needs. A micro-credit project failed because it focused solely on women as beneficiaries, which led husbands to withdraw their support.

The MGLSD and other organisations use several gender-sensitive indicators to evaluate the success of projects. These include the number of women involved in decisions at leadership levels, the number of girls able to access education and the number of rural women able to access clean water. However, only $64 \%$ of organisations monitored and evaluated their projects/ programmes.

\section{Conclusions and recommendations}

Women scientists. Men still dominate the forestry sub-sector in the civil service partly due to few girls opting for science subjects at A level culminating into a limited number of women scientists. The forestry sector and civil society organisations should encourage girls to pursue a career in science, and in forestry in particular.

Gender mainstreaming. Most gender mainstreaming policies lack legal provisions to ensure compliance. The environment subsector should ensure its organisations and partners are supported by the MGLSD to develop gender mainstreaming guidelines for all operational units. The NFA and District Forest Services (DFS) should also work closely with NGOs to build capacity for gender mainstreaming. Finally, the gender capacity of organisational staff should be strengthened through technical assistance. In addition, to address limited commitment by the FSSD and NFA in implementing gender policy, the MWE should develop a gender strategy to guide the sub-sector in mainstreaming gender in planning, monitoring and evaluation.

Application of laws. Gender considerations in national laws are not reflected at lower levels of government. The MGLSD should help district and local governments translate gender laws and policies into action plans. It should also make explicit reference to tree and forestry issues in the Uganda Gender Policy.

Land ownership. Women own only 7\% of land in Uganda, limiting their participation in private forest management and tree planting. The NFA and FSSD should work with civil society to lobby for stronger laws to protect women's land security. Moreover, district and local governments should develop capacity to enforce women's land tenure rights during land transactions.

Credit. Women's limited control over productive resources affects access to credit, which is vital for initial investments in tree planting and support from the NFA. The NFA should advance funding to women as an incentive to take part in private forest development and central forest reserves.

Community forest management. The NFA lacks the capacity to ensure that men, women, youth and the poor are actively involved in CFM processes. It should collaborate with the MGLSD and the Ministry of Agriculture, Animal Industries and Fisheries to build capacity for mainstreaming gender in their programmes. The NFA should also work with civil society, the private sector and development partners to address gender concerns in forest management.

Negotiations. The CFM negotiating process is lengthy and in English, a language only a few community members understand. This discourages participation, especially of women. The NFA should simplify CFM guidelines and make them available in local languages.

Work burden. Most women, especially among the poor, are overburdened with household chores that leave limited time to participate in forestry management. The MWE should promote labour-saving technologies such as firewood-saving stoves, agroforestry and animal draught power. All stakeholders should intensify gender sensitisation at the community level.

\section{Acknowledgements}

AUPWAE wishes to acknowledge all the people who cooperated by providing information for the study, executive members and staff of NGOs, the government officials in ministries and agencies, and the District Forest Officer Mpigi. Special thanks also go to the team members from the School of Forestry, Environment and Geographical Sciences for the continuous advice rendered. We wish to express our gratitude to the Austrian Development Agency (ADA) for supporting the study. We thank Esther Mwangi and Anne Larson of the Center for International Forestry Research for providing methodological input and for overall coordination of the research. 


\section{References}

Ellis, A., Manuel, C. and Blackden, C.M. 2006 Gender and economic growth in Uganda: unleashing the power of women. World Bank, Washington, DC.

Empaform 2006 Participatory forest management initiatives in Uganda: key implementation concerns and recommendations for policy actions. Empaform Policy Briefing Paper No. 1. Empaform, Kampala, Uganda.

Gombya-Ssembajjwe, W.S. and Banana, A.Y. 2000a Collaborative forest management in Uganda: the case of Buto-Buvuma Forest Reserve, Mpigi District, Uganda. In: GombyaSsembajjwe, W.S. and Banana, A.Y. (eds.) 2000 Communitybased forest management in East Africa. Makerere University Printer, Kampala, Uganda.

Gombya-Ssembajjwe, W.S. and Banana, A.Y. 2000b Community participation in forest management: the case of Buto-Buvuma Forest Reserve, Mpigi District, Uganda. Proceedings of the international workshop on community forestry in Africa. Participatory forest management: a strategy for sustainable forest management in Africa, 63-70. Food and Agriculture Organization. www.treesforlife.info/fao/Docs/P/X7760B/ X7760B11.pdf.

Japan International Cooperation Agency (JICA) 2007 Uganda: Country gender profile. Japan International Cooperation Agency, Tokyo, Japan. www.jica.go.jp/activities/issues/gender/ pdf/07uga.pdf (10 March 2012).

Katungi, E., Edmeades, S. and Smale, M. 2006 Gender, social capital and information exchange in rural Uganda. CGIAR Systemwide Programme on Collective Action and Property Rights
(CAPRi) Working Paper No. 59. www.ifpri.org/publication/ gender-socialcapital-and-information-exchange-rural-uganda (10 March 2012).

Kazoora, C., Acworth, J., Tondo, C. and Kazungu, B. 2006 Forestbased associations as drivers for sustainable development in Uganda. IIED Small and Medium Forest Enterprise Series no. 15. International Institute for Environment and Development, Edinburgh, UK.

Kugonza, A., Buyinza M. and Byakagaba, P. 2009 Linking local communities livelihoods and forest conservation in Masindi District, North Western Uganda. Research Journal of Applied Sciences 4: 10-16.

Ministry of Finance, Planning and Economic Development (MoFPED) 2005 Uganda poverty status report 2005: progress in implementing the poverty eradication action plan. Ministry of Finance, Planning and Economic Development, Entebbe, Uganda.

Ministry of Water and Environment (MWE) 2002 The national forest plan. Ministry of Water and Environment, Entebbe, Uganda.

Tenywa, G. 2008 Uganda: politics, corruption fuelling destruction of forest reserves. New Vision, 2 November. Www. newvision. co.ug/D/9/34/657598.

Uganda Bureau of Statistics (UBOS) 2009 Statistical abstract. Uganda Bureau of Statistics, Entebbe, Uganda.

Wasswa-Matovu, J. 2010 The effects of transactional costs on community forest management in Uganda. Organisation For Social Science Research in Eastern and Southern Africa, Addis Ababa, Ethiopia.

\section{Austrian}

Development Cooperation

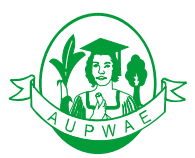

Association of Uganda Professional Women in Agriculture and Environment 